Velimir ŠEĆEROV

\section{The Danube as a factor of physical integration of Serbia and Europe}

\section{Introduction}

The River Danube and Danube basin cover one third of the European continent. Considering the river's entire catchment area, the Danube basin lies in 18 countries: all of Hungary and Romania, part of the Czech Republic and larger parts of Slovakia, Austria and former Yugoslav republics, a large part of Germany (Bavaria and part of Baden Wurtemberg), part of Bulgaria and parts of former Soviet Republics, such as Ukraine and Moldova. (Table 1) Mountain regions enclose the Danube basin: the Alps in the west, Carpathian Mountains in the north and east and Balkan, Rodopi ranges in the south. Today the Danube has a central position in the internal European navigable river network, with a length of $35.000 \mathrm{~km}$, which service an area of $817.000 \mathrm{~km}^{2}$. The river carries enormous quantities of water to the Black Sea (200 billion $\mathrm{m}^{3}$ annually), which are also used for fuelling large hydroelectric plants, and creates a diverse delta with several canals.[1] Important tributaries, such as the Inn, Sava, Drava, Tizsa, Drina, Morava etc. form its rich hydrological body. As the largest European river course $(2.857 \mathrm{~km})$ [2] it connects more than 500 million inhabitants and brings together the economically most attractive areas of the old continent. Considering the river's entire area, its links to the North Sea and planned links to the Adriatic and Aegean Sea, The Danube is surely the most important natural resource of central Europe. The trans-European navigable route, formed by canals linking the Rhine, Maine and Danube [3] measuring $3.505 \mathrm{~km}$, offers new possibilities for development of transport, trade and other economic sectors.

Table 1: Countries in the Danube basin (in the wider sense)

\begin{tabular}{|l|c|}
\hline $\begin{array}{c}\text { Countries in the } \\
\text { Danube basin }\end{array}$ & $\begin{array}{c}\text { Share of territory } \\
\text { in the Danube basin (\%) }\end{array}$ \\
\hline Germany & 16 \\
\hline Switzerland & 6 \\
\hline Austria & 97 \\
\hline Czech Republic & 29 \\
\hline Slovenia & 78 \\
\hline Hungary & 100 \\
\hline Slovakia & 95 \\
\hline Croatia & 58 \\
\hline Bosnia and Herzegovina & 78 \\
\hline Serbia and Montenegro & 91 \\
\hline Romania & 100 \\
\hline Bolgaria & 46 \\
\hline Moldavia & 38 \\
\hline Ukraine & 5 \\
\hline
\end{tabular}

* The share of territories in Italy, Poland, Albania and Macedonia is very small (less than $2 \%$ )

Source: Danube Space Study, Österreichisches Institut für Raumplanung, September 1999.
The official source of the Danube is in Donaueschingen; as such it was already mentioned in the times of Tiberius. Close to the spring itself, two other rivers meet, the Breg and Brigach, which together form the river's source. Especially inhabitants of the mentioned place have often questioned this fact. Thus, although this great European river's source is officially recognized, many consider the spring of the Breg, which is $48,5 \mathrm{~km}$ away from Donauesingen, as its source. ${ }^{[4]}$

Hypothetically some 60 million years ago (tertiar-eocen) the Danube began somewhere around modern-day Vienna in the Sarmat Sea, which covered entire south eastern Europe. After numerous tectonic movements and changes, its present form emerged, although in history it was divided into two parts: the Danube (upper course) and Histar (lower course), which nevertheless form a single river. ${ }^{[5]}$

With respect of the importance of the Danube for comprehensive development of the European continent, the Danube, acting as a development axis in the countries it flows through, has as a rule made its adjacent areas more prosperous and with best potentials, except for areas, subject to border regimes and whose development was slower or hindered by the fact that they were defence areas and strategic military territories (limes, Banat military border, Iron curtain etc.). Therefore it is quite clear, why the economic and natural potentials of the Danube were interesting not only for nations that are naturally tied to the river, but also those that wanted to exploit the numerous potentials of the region. Historically speaking, this area was the setting for many conflicts and the people living there often had to defend (or conquer) its various parts.

On the other hand, it is characterized by cooperation between its various countries, independently of different divisions that existed (and still exist), whatever their nature: ideological, national, cultural, religious, economic or other.

\section{The Danube basin in Serbia}

The space of Serbia and Montenegro in relation to the Danube has significantly changed to the space of former Yugoslavia. With respect for the planning method and spatial organisation before and now, we can clearly distinguish changes in the Danubian space in Serbia between the North, along the border with Croatia, and the South, along the borders with Romania and Bulgaria. Differences are obvious not only in fields related to physical planning, but also in the settlement network, infrastructure and industry. In short, until 1991, the area of the Danube that is now the border region with Croatia was planned as a central national zone with attributes quite different from present ones or in relation to places along the border. The consequences were strong development pulls in the area, which were based on recognised natural contents and regional characteristics, i.e. a wide river, which are, as a rule, the axes of development. Important towns on either side of the river (Sombor, Apatin, Osijek, Vukovar etc.) positioned themselves and ensured stable development that was granted by natural potentials, communications and the given strategic setting. Then the condition became quite different.[6] The inherited spatial organisation, planned and developed for decades, simply didn't exist anymore. The border, just like any other limit, but additionally coated with 
specific dimensions of ethnic fighting in the recent past and constant low intensity tensions, was sufficient in preventing serious ideas about real spatial actions, thus also radically changing and conditioning development components of the region.

Even if we state that space is an indivisible category and cannot suffer administrative boundaries (borders), in the case of Serbia and Croatia during the last twenty years, this space became clearly differentiated. Today nevertheless, the situation is much better. Institutional cooperation is slowly recovering and the lax border crossings, where visas between the two countries are not demanded, are helping quicken important improvements in bilateral cooperation. There are also signs of joint planning actions and the formation of joint planning regions.

On the other hand, the remaining part of the Serbian Danube has maintained its character and functions. The lower Danube in Serbia (from Gradište to Kladovo) was always subject to a border regime. The already mentioned and in history often reinforced boundary on the Danube (Roman limes, Austro-Hungarian border, limit of the Warsaw pact countries etc.), now between Serbia and Romania, is becoming softer and with better prospects for cross-border partnerships and cooperation, than the border with Croatia. With Romania opening towards its neighbours, to European planning and development trends, a new coherence about natural assets is emerging, as well as a consciousness about the necessity of joint care and planning of the Danube.

The Djerdap is a constant subject of interest for many archaeologists, art historians and culturologists from both sides. Apparently they were the first to establish contacts and create conditions for synchronised actions in the discovering and protection of cultural-historical treasures of the area. Their efforts are shadowed by the organisation of multi-national (Danubian) festivals, which take place in border towns [7] and are the first attempts at cooperation, which could later include all other activities that occur in the region. [8]

The earlier stated facts lead us to a possible division of the Danubian space in Serbia, which relate to the system of former and future planning and spatial use: (Figure 1)

- Upper Danube - area along the Croatian border that has significantly changed its recent spatial and functional attributes and corresponds to the part from the Danube's entry into Serbia near Batina (Bezdan) until Bačka Palanka;

- Mid Danube - area from Bačka Palanka to Rama, i.e. the Danubian space in Serbia has maintained its former characteristics and doesn't need changed planning or territorial management, and furthermore encompasses the objectively most important centres in Serbia;

- Lower Danube - area along the Romanian border from Rama to Prahovo, with characteristics that have always existed, but with better prospects for cross-border cooperation and partnerships.

D. Perišič (1967) also gave a possible division of the Danubian space in, but because it was done only for the spatial plan for the building of the hydroelectric power plant Djerdap, it applies only to the area from Belgrade to the Bulgarian border and relates only to the functional zones of urban centres along the Danube. Similarly B. Stojkov, M. Vujošević and S Subotić (1997) divide the Danubian area into two parts, i.e. from Bezdan to Belgrade and from Belgrade to Prahovo (the Bulgarian border) as a balanced extensive variety of limiting the area. Using these experiences, which stem from geographical, administrative, historical or even political axioms, which are coupled with actual present conditions, we proposed a division of the Danubian region into three parts, especially in consideration of cross-border cooperation and differentiation from former planning and solutions for the region.

The beginning of the 21 . century has opened a wider future perspective for countries in the Balkans. All the countries in the region have several common features:

- Opening to Europe and neighbours;

- (Un)stable political situation;

- Commencement or completion of regionalisation of own territory according to European directives;

- Privatisation that has ensued everywhere and significantly differs in scope and success from country to country;

- Dependency on foreign investment and investment into revitalising or stimulating domestic economic potentials;

- Possibility for joint spatial planning of neighbouring territories without regard for administrative divisions.

\section{The Danube basin in Europe}

After a volatile history and many tensions around the Danube, European trends and planned development are taking a different course, built on activation and exploitation of the potentially most attractive European territories. Many plans and studies focused on the integration and coordination of planning strategies of territorially close countries, but also those that are geographically distant yet have traditional or potential similarities. ${ }^{[9]}$ Real, functional cooperation begins by establishing sub regional cooperation between border regions in neighbouring states in selected key areas, to which regions from the wider area could join in later and the list of important and common themes would be constantly lengthened. Cooperation conceptualised in this fashion would lead to constant planning or real implementation of articulated ideas, which could always be jointly intervened upon, depending on the passage of real events in the field.

Natural features are key links for such cooperation, especially the Danube itself with its hinterland, while in the wider sense the Danube with its entire basin. In Europe there is surely no integrative measurement stronger than the Danube, therefore the attention given to the river and its space in Europe, as a continent, or locally, in particular countries, is not surprising. The Danube basin's population has been stagnating during the last two decades; its growth rate is $2 \%{ }^{[10]}$ with enormous regional differences (e.g. Albania and Germany) noticeable also within the boundaries of particular countries (e.g. Vojvodina and Kosova and Metohia in Serbia).

A short list of facts about the Danube in Europe reflect the river's character for the countries it flows through that accentuate the need for cooperation, partnerships and integration:

- On the entire course of the Danube almost $1.000 \mathrm{~km}$ $(38 \%)$ are in border zones, i.e. on these parts the river is the natural and administrative boundary. Only in four places three national borders meet;

- On the Danube there are 149 bridges, of which only 8 $(5 \%)$ are between two countries:;11] 
- On the Danube there are 14 hydroelectric plants, of which 2 are in Germany, 9 in Austria, 1 in Slovakia and 2 between Serbia and Romania. In the area there are also 9 nuclear power plants.

The Danube connects exceptionally wealthy areas of Europe, but it is also the link between the rich and the poor, the link between east and west, the link between various systems, religions and cultures. Today everybody plans the Danubian basin. It is done in various ways: bilaterally, in ternationally, globally, internally and partially. Attention is given to all aspects of human activity; various direct or indirect strategies of political, spatial, economic and other development are being designed. Therefore it will seem that all the mentioned documents deal with the Danube although the river or its territory weren't their main theme. There are nevertheless several common points mentioned in all the actual planning documents presently being produced in Europe:

- Plans (studies, analyses etc.) are of the structural type;

- Guidelines and principles (policies) are given and not definite solutions;

- They function integratively, especially in the sense of connecting countries within the EU and those beyond;

- They accentuate codification of planning methodology and development policies;

- They are based on EU experiences and more or less respect different approaches;

- They offer stimulation and support by various EU countries to less developed countries in the form of coordination, motivation (by integration in various European projects and organisations, SECI, PHARE, ECE etc.) and networking.

Generally speaking the goals of such actions are to bring closer (equalize) European countries by establishing tighter cooperation and assistance to former communist countries during transition into a new system. The nature and character of cooperation in the Danubian region are determined mainly by economic structures in the particular countries in the region and the trend for adapting their structures to more developed countries. This adaptation necessarily implies significant growth of the tertiary (service) sector in the domestic product. Undoubtedly the Danube, seen as a natural resource for development of economy, trade, transport and tourism, as well as a backbone of regional cooperation, offers all neighbouring countries a comparative advantage in the process of economic restructuring. (E. Stojić-Karanović, 1994)

Until the nineties of the last century exploitation of this natural resource was sincerely insufficient and inadequate, without rational organization, which would take care of economy, ecology, culture and other interests of the settled area. This was mainly a consequence of political division [12 and the cold war, with even more tensions during the last years with new problems caused by various crises, wars and sanctions (primarily in former Yugoslavia). Because of such conditions and mainly political reasons, which have nothing to do with the geographical setting, the territory of former Yugoslavia was in all plans depicted as a grey smudge. Today the conditions are different and Serbia and Montenegro are assuming their rightful place as players.[13] Furthermore, there are other serious problems tied to above all a level of economic efficiency and economic competitiveness of transition countries, coupled with their integration in financial and trade flows in the EU.
Moreover, it is impossible to speak about same involvement in methods of exploitation, protection and treatment of the Danube in the different countries that are at various states of economic development. Differences can emerge even in understanding the key term in contemporary planning - sustainable development. Global planning trends (the World summits on sustainable development in Rio da Janeiro (1992), Istanbul (1996), Johannesburg (2002)) emphasised sustainable development as the possible way for integrating the economic, social and ecological environments with $\mathrm{mi}$ nimal negative effects of one sector's development on the others. $\left.{ }^{14}\right]$ Although the principles of sustainable development have been widely accepted, it is logical that there are no equal preconditions and potentials for their adequate enforcement, if we consider the various levels of, above al economic development of the countries, which should introduce them into domestic practise. The tension usually starts with the statement that countries that have reached a higher level of economic and technical development are now ready to turn to nature protection (since they have no need for devastating their own environment anymore) and limit its further. However, insisting on respect for spirit and matter, i.e. all aspects of human activity, establishing responsibilities for all actors in the environment, recycling, restoration and revitalisation, attempts at reorienting to economical, safe and recyclable energy resources, renovating an preserving cultural and historical values, as well as the interdependence and connectedness of all spatial elements and life in general, don't always depend on the material well-being of particular countries. In short, the idea of sustainable development in all its elements is truly positive, especially in the case of the Danube and its basin. The second question is, whether it is feasible and possible, if we take into account all objective circumstances and the mental framework of humans themselves as stakeholders in space, i.e. their constant desire for profit, with no consideration of the environment.

The contemporary determination in countries of the Danube basin is that the Danube should be planned integrally and in the spirit of sustainable development. By joining the region from Germany to the Black Sea, the Danube macro-region was formed. As said by D. Tošić, from the geographical point of view, the Danube basin is a homogenous and complex region with three clearly differentiated sub-regional entities: the Bavarian, Pannonian and Vlacho-Pontian Danubian basin, which are mutually divided by the Vienna Gate and Djerdap Gorge. The first two are in Central Europe, the latter in South-eastern Europe. (D. Tošić, 1998.) Today the Danube macro-region is planned integrally by cross-border, trans-national and trans-regional cooperation. [15] With the participation of all Danubian countries in the formation of Danubian studies and projects a planning and development correlation and subordination was achieved, whereby representatives of all the participating countries stated their thoughts, visions, data and proposals. The entire codification, cooperation and common strategy are leading to a unique Spatial plan (strategy) of sustainable development of the Danube basin, which before completion demands numerous methodological and systemic changes, innovation and modernisation of planning and political standpoints. This integrative process and the entire integration of the territory will also be the preconditions and primary goal of such a plan. Achievability of this idea will in many ways depend on identification of issues, needs and possibilities, preparedness of political leaderships to commence 
solving problems and on the level of responsibility given to regional institutions and organisations, which is needed to implement the plan.

Insisting on cross-border cooperation in Europe has its roots stretching thirty years back to the idea of forming socalled euroregions, i.e. border regions that are "although divided by political borders mutually linked by various bonds, such as economic, social, cultural or even by marriage«. (Sieminski, 1999) As put by M. Grčić (M. Grčić, 2002) this idea was realised in three phases: 1) 1969 - formation of the European association of cross-border regions (EATG), 2) 1981 - adoption of the European convention on border and cross-border regions, 3) 1985 - adoption of the Declaration on local self-government, all leading to the EU declaration on regionalisation. Grčič adds that the first euroregions or cross-border regions emerged from corresponding contracts and agreements between neighbouring countries (two, three and rarely more) concerning border cooperation. He explains the beginning of euroregions by three basic goals: political (EU integration strategy), socialeconomic and environmental, which were conditioned by, similarly, three reasons:

- Lagging behind in border areas in the field of economy,

- Treatment as problem areas precisely because of their economic inferiority and are aided in development by the whole country,

- The need for cooperation with neighbouring areas on the regional and local level because of necessities of solving issues of exchange of goods, protection of the living environment, improvements in science, technology, tourism etc.

After thirty years of European experiences in the formation and management of euroregions, today we can distinguish between three basic types (M. Grčić, 2002):

- Euroregions within the European Union territory (Western Europe). Regions characterized by equalized financial status and political and economic stability. Numerous programmes and especially the INTERREG I project, adopted in 1990, support links between border areas.

- Euroregions created on the European Union's outer borders. Their basic goal is to integrate countries undergoing post-communist transition to EU countries. Many examples of this type of cooperation caused the opening widening of new European initiatives, leading to the INTERREG II programme, adopted in 1994. After initial actions around the edge, EU programmes extended into southeastern Europe and the East, with the compulsory participation of at least one EU country as the project leader. Thus the projects ESTIA, VISION PLANET etc. were established. They also included the territory of Serbia and Montenegro, which will be elaborated later.

- Euroregions in countries outside the European Union. The third type of euroregions also relates to the territory of Serbia and its neighbours. Such regions exist in southeastern Europe. We are dealing with cross-border cooperation between regions in Serbia, Hungary and Romania, assembled in the first Balkan euroregion Danube-Kris-Moris-Tisza. Although interested countries exercise possibilities of independent choice of method and form of cooperation, recommendations by the EU cannot be avoided; numerous development documents point out exact places of possible and necessary cooperation in these countries. Such cooperation is aligned to natural features of the terrain and accessibility in the political and economic sense.
The second and third types of euroregions are fairly recent. The early years of the last decade of the 20. century, which coincided with the cold war ending, political blocks ceased to exist, thus allowing possibilities for international and interregional cooperation to begin. The production of many planning concepts ensued in all societal spheres. The goa of these concepts was to harmonise development in western and eastern countries by activating common natural potentials. A whole myriad of plans dealt with, amongst other, the southeast European territory, which was similarly during the last decade of the 20 . century, the field of many crises and conflicts. Planning nevertheless survived, cooperation has been established and spatial (and other) conflicts are being resolved. These documents are extremely important for all countries in the Danube basin that see their prospects for development also in the river's potentials and cooperation across it.

Regional cooperation can help implementation of the mentioned plans and strategies, principles and methodologies. All point out the importance of corridor VII in Europe. Joint planning is increasingly becoming a reality but also a dire need. In this way all countries along the Danube are tracking their route to joint European planning and are finding their place on Europe's communication map. Serbia is also setting its position and simultaneously managing and protecting its space from further devastation and pollution. This is also the only way to activate the Danube's values and its surroundings, without limitations from administrative divisions but by respecting inherent specifics and particular positive experiences.

Asist. Velimir Šećerov, M.Sc., physical planner, University

in Belgrade, Faculty of geography, Institute of physical planning, Belgrade

E-mail: app2000@EUnet.yu

\section{Notes}

[1] The Danube officially flows into the Black Sea in Sulin

[2] This is the most often stated length of the Danube River (other slightly differing data is also available, depending on the specified origin).

[3] The opening of the canal Rhine-Maine-Danube in 1992 enabled connections between the Black and North Sea, as well as links to the ARA harbours (Antwerp-Rotterdam-Amsterdam)

[4] Claims on the Danube's source go so far that some mention its originating from a tap, which lies close to the Breg's spring and in fact provides the river's initial water! (K. Magris, 1988.)

[5] Ernst Nenjeklonjsky (1882-1964), civil engineer, who had a life-long relationship with the Danube and its borders, explained that strictly geographically speaking, the upper course covers $1.100 \mathrm{~km}$ till the confluence with the river March, while according to international law the length is $2.050 \mathrm{~km}$, all the way to the Iron Gate, i.e. former Ottoman border.

[6] The status of formerly important cities and spaces on both sides of the border is today very different. For example Kopački Rit, a nature reserve in former Yugoslavia, was an important strategic war zone during the 90s and a desolate, devastated place today. The formerly strong industrial centre Vukovar shares the fate.

[7] In the year 2000 a joint three-day seminar was held in Kladovo and Turnu Severin, complemented with concerts, painting exhibitions etc, under the title Cultural values as the foundation for physical integration of countries in the Danube basin. Following proposal by the European Union 
and initiative by experts from Serbia (B. Stojkov), Romania and Bulgaria, this project opened possibilities for further cooperation even in other fields. The event was followed by a joint compendium and publishing of the first issue of the magazine iron Gate, which will be edited by delegates from the three countries and deal with problems of cross-border municipalities along the Djerdap (Iron Gates)

[8] The document VISION PLANET specifies 5 zones of crossborder cooperation on the Danube. Two include the territory of Serbia. The first is at the entrance area, implying cooperation with regions in Croatia and Hungary, while the second is at the exit from Serbia at Djerdap (Iron gates), which includes regions on the Danube's left bank in Romania and Bulgaria.

[9] Links can be cross-border, trans-national or trans-regional.

[10] Data is taken from the document VISON PLANET.

[11] An interesting feature is that 3 of the 8 international bridges are between Serbia and Croatia. Until the recent separation of the former Yugoslav Republics in 1991 they were internal, national bridges.

[12] The magnitude of a great river as a factor of disintegration is manifested on the $470 \mathrm{~km}$ border between Romania and Bulgaria where there is a single bridge. The $222 \mathrm{~km}$ border between Serbia and Romania is similar.

[13] Indeed political conditions still exist, which disable full integration with other surrounding countries, but the planning principles from the Physical plan of Serbia have found their place in other plans covering the territory. At the time Yugoslavia wasn't a member of international organizations dealing with the Danube, thus access to funds for particular projects is not possible. The most important fact nevertheless is that it is represented and returned to European planning activities.

[14] Officially the term sustainable development was globally accepted in Rio de Janeiro in 1992, when the AGENDA 21 was adopted, a document signed by almost all countries of the world, including Yugoslavia. Following this summit many others were held, all the way to 1996 and Istanbul, when the HABITAT II declaration was adopted.

[15] On result of cooperation was the completed project Danube Space Study.

\section{Illustrations}

Figure 1: Division of the Danubian space in Serbia

Figure 2: Central European, Adriatic, Danubian and Southeast European space (CADSES)

(Source: Vision Planet-Strategies for Integrated Spatial Development of the Central European Danubian and Adriatic Area, Background Report, prepared by the Working Team, April, 2000)

Figure 3: Zones of cross-border cooperation and protection

(Source: Vision Planet-Strategies for Integrated Spatial Development on the Central European, Danubian and Adriatic Area, 2000)

For sources and literature turn to page 57. 